\begin{tabular}{c} 
International Journal of Engineering \& Technology, $7(4.38)(2018)$ 1044-1046 \\
International Journal of Engineering \& Technology \\
WPC \\
Website: www.sciencepubco.com/index.php/IJET \\
Research paper \\
\hline
\end{tabular}

\title{
Effectiveness of Maintenance and Inspection Process using Augmented Reality Application
}

\author{
Faieza Abdul Aziz, Eisa Alostad, Kamarul Arifin Ahmad, Shamsuddin Sulaiman and Ooi Chun Hoe \\ Universiti Putra Malaysia, Department of Mechanical and Manufacturing, Faculty of Engineering, 43400, Serdang,Malaysia
}

\begin{abstract}
Augmented reality is the integration of digital information and user's real life environment. It overlays virtual information on top of existing environment to user's perception towards the reality. Technicians and engineers in automotive industry at workshops today have mountains of data and information for diagnostics and repair. The worker must search for the information, and then manually check to see if he can assess the problem and repair what is not functional. Worker must refer to a printed drawing of the testing body, with the inspection parts marked on this drawing. Augmented reality application is proposed to replace these conventional references to eliminate their disadvantages. The objectives of this paper are to develop an augmented reality applicationto and evaluate the effectiveness of augmented reality application developed. Vuforia, Blender and Unity were used to develop augmented reality application due to their easy to use features. The application developed will be tested by respondents to conduct inspection and maintenance process using both conventional references and augmented reality application developed. Survey will also be carried out to evaluate the acceptance level of locals towards augmented reality application as well. The technology has proven to be popular in the automotive industry.
\end{abstract}

Keywords: Augmented Reality, Automotive, Inspection, Maintenance, Process

\section{Introduction}

Automotive inspection is the process of examining a vehicle to ensure that it conforms to regulations regarding to safety or emission or both. The process is usually mandated by governments in most of the countries in the world. Examples of automotive inspection are suspension test, brake test, smoke test and etc.

Automotive maintenance is the process of servicing or replacing vehicle parts and fluids. It is a crucial process to ensure that the safety, reliability, drivability, comfort and longevity of vehicles are being maintained. Unlike inspection, automotive maintenance can be carried out by anyone. Basic maintenance can be carried out by owner of vehicle. Advanced maintenance should be carried out by experts in any automotive maintenance outlet in the country. Examples of common automotive maintenance are engine oil and oil filter replacement, timing belt replacement, spark plug replacement and etc (Henry, 2013).

In today's world, even the expertise require to refer to prints, manuals or computers with detail procedures, components data and safety information to aid them in their inspection and maintenance process of automotive industry (Henderson \& Feiner, 2007). These artifacts must be present within the maintenance personnel's reachable area, often far from the area which inspection and maintenance take place. This causes the maintenance personnel to constantly switch focus from the process to the references and back to the process again. This directly contributes to the risk of human error to happen. These make the inspection and maintenance process more inconvenient and complicated.

The objectives of this paper are to develop an augmented reality application to help during vehicle inspection process to be more organized and to speed up the overall process of inspection. This work also evaluate the effectiveness and acceptance level of augmented reality application in inspection and maintenance compared to normal automotive maintenance training.

\subsection{AR in Automotive Industry}

$\mathrm{AR}$ is now becoming a tool for designers and engineers in the automotive industries in the need to cater increasing demand in variety of car models and short product life cycle. Virtual and mixed technology are more favoured in addition to CAD technology so that the development process can be speed up and optimized (De Sa \& Zachmann, 1999). The elevation of AR since the past half-decade not only provides for semi-immersive environment but also has great potential in solving problem before product being manufactured.

Automotive industry amongst other industry has also been using $\mathrm{AR}$ as a new promoting approach for their product. Volkswagen was the first to introduced AR marketing campaign by AR using tracker technology in 2008. Volkswagen also created an AR campaign for Golf model where people can see an augmented reality version of Golf via their website in 2010. At Geneva Auto show in 2012, Volvo gave user the opportunity to see the inside of Volvo V40, a newly launched model. Using tablet, the app used $2 \mathrm{~d}$ marker to emulate $3 \mathrm{~d}$ images augmented reality experience (Samuely, 2013).

\subsection{AR In Automotive Inspection}

Information acquisitions are most time consuming and are exposed to errors in which traditional manual method are commonly used (Chung, 2002). In 1993, a system was designed for five dif- 
ferent inspection systems for automotive electronics companies which are human inspection, computer-search human-decision, human-computer decision-sharing and automated inspection (Hou, Lin, \& G, 1993). The result of the study showed that the two hybrid inspection systems influenced by human decision have a better performance than the automated inspection.

Spatial Augmented Reality (SAR) and HMD can be combined to display information to operators and can be personalized towards individuals (Zhou, et al., 2012). Spot Welding is a critical process in car manufacturing as it makes car safer and reduce in rattles and road noises. Sheet metal parts are joint together using spot weld technique that make joined part stronger and uniform in appearance. In spot welding inspection process, SAR creates a new alternative in designing an inspection system that $A R$ can aid to support inspectors and improve efficacy. Portable laser projector based SAR specifically allows visual data being projected on arbitrary surface and within physical work cell, user can get real data information

\subsection{AR In Automotive Maintenance}

AR has become a trend in consumer market since it can create interaction with users, however for industry sector especially automotive maintenance, AR represent high expectation and user demand due to failing cost and requirement (Olieveira, Farinha, Singh, \& Galar, 2013). AR application development in automotive maintenance and repairing process uses various overlay method with mobile hardware. One of AR advantage in maintenance is the capacity to superimpose information and invisible effects on real time environment such as procedures or instruction for equipment.

Maintenance and repair operations are potential areas that can be use as subject matter for application of AR. These activities are mostly done manually by skilled operators following rigorous procedure in documenting and carrying out maintenance works in relatively static and predictable environment. Manual process means that operator needs to physically navigate tasks in maintenance and this can be extremely time consuming (Prakash \& $\mathrm{Ku}-$ mar, 2011). Even the most trained maintenance personnel still need to follow manuals and with restricted space,

Application of AR not only limited for car manufacturer but also for customer. Customer can do self-vehicle maintenance at their own home with mobile AR application. Audi has partner with Metaio and created AR mobile application that can recognize and exemplify over 300 elements of Audi A3 model so that user can understand more about the vehicle (McCarthy, 2013). Hyundai has produce Hyundai Virtual Guide using AR system (Turpen, 2015). The application was able to identify over 45 features of 2015 Sonata and user can see insight use, maintenance and repair procedure when relevant parts of the car viewed to IOS mobile devices camera.

\subsection{Method of Research}

The devices used in this work were smart phone, laptop and VR Box. The model of smartphone that was used in this project is Samsung Galaxy Note II N7100. Laptop chosen was ASUS Transformer Book Flip TP500L that capable to use 3D modeling tools and must be able to support augmented reality tools and 3D modeling tools without causing technical problem to the user. Lastly experiments are done to evaluate the effectiveness and acceptance level of augmented reality application in inspection and maintenance compared to normal automotive maintenance training.

In order to assist users to keep smartphone infront of their view during the process without holding it by hand, VR Box is used. It is a device which allow users to insert their smartphones into it's front space and allow user to wear it like glasses. With this, users can see through their smartphone without holding it in front of their eye with hands. Figure 1 shows VR Box usage.

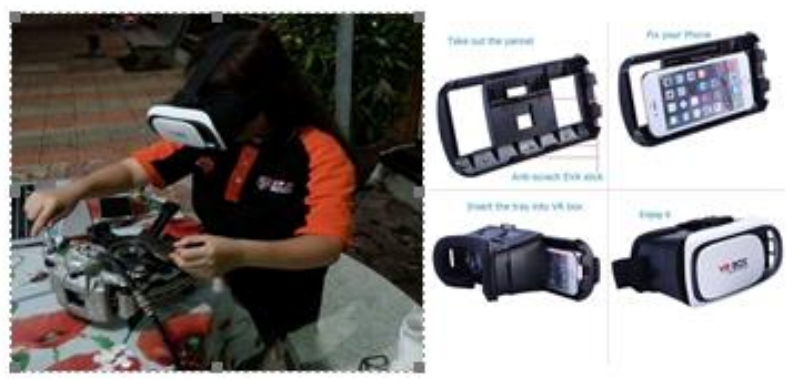

Figure 1:. VR Box Usage

The area of vehicle inspection and maintenance chosen in this project is general inspection and maintenance of vehicle. Below are some examples of general inspection and maintenance of vehicle:

a) Brake pad inspection and maintenance

b) Brake disc inspection and maintenance

c) Brake master cylinder replacement

The processes mentioned above will be integrated into development of augmented reality application.

\subsection{Application Development}

The software involved in this stage of development are Vuforia and Unity. Vuforia is a tool that aids it's user in developing augmented reality application while Unity is platform which allow users to develop software such as games and mobile application. Vuforia need to be downloaded in .unitypackage format and imported into Unity workspace to give Unity the features to develop augmented reality application. Augmented reality target markers such as qr code can be managed by using the same concept between Vuforia and Unity.

The last part of the development process is application development, a process where all animations and required elements such as $\mathrm{qr}$ code markers, augmented reality settings, programming scripts etc are integrated into one single .apk file package. Figure 2 below shows animated maintenance process through the use of augmented reality mobile application in smartphone.

Currenlty the authors are in a stage of evaluating the developed an augmented reality application that can assist inspection and maintenance in automotive industry in Kuwait. The results will be compared with normal training method.

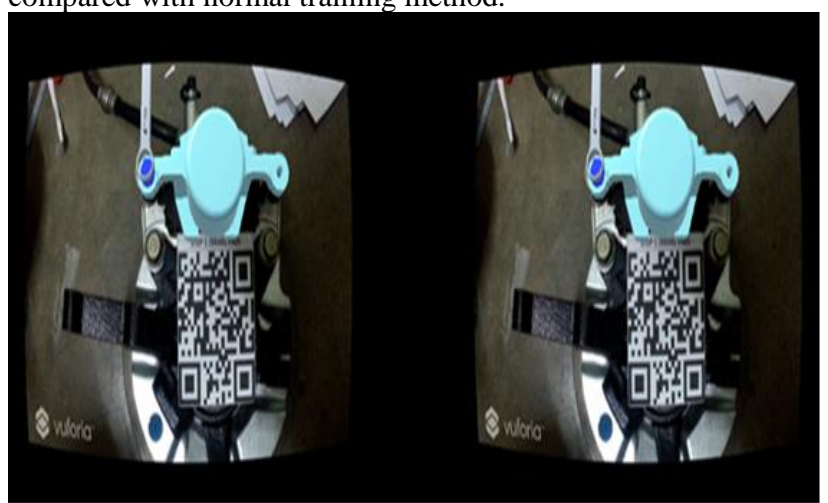

Figure 2: Animated Maintenance Process via Augmented Reality Mobile Application 


\section{Conclusion}

AR technology has been proven to be popular amongst automotive manufacturer which add another dimension to automotive industry. Furthermore, overlaying contextual information into real work environment is able to increase labor and productivity. Adoption of AR can speed up problem solving and influence data quality. A holistic approach is necessary towards human interaction, financial and technological aspects in adopting AR in automotive industry. In conclusion, AR application will benefit the automotive industry and more work should be done to incorporate AR in many aspects of process in automotive industry.

\section{Acknowledgements}

This research is supported by PIPPT grant 6387700 .

\section{References}

[1] De Sa, A., \& Zachmann, G. (1999). Virtual Reality as a tool for verification of assembly and maintenance process. Computer \& Graphics, 23(3), 389-403.

[2] Gusikhin, O., Rychtyckyj, N., \& Filev, D. (2007). Intelligent systems in the automotive industry : applications and trends. Knowledge and Information System, Volume 12, (Issue 2,), 147 168.

[3] Henry, A. (2013). The Preventive Maintenance You Need to Do On Your Car (and When). Retrieved from http://lifehacker.com/the-preventative-maintenance-you-need-todo-on-your-car-1394196018

[4] Henderson, S., \& Feiner, S. (2007). Augmented Reality for Maintenance and Repair (ARMAR). Air Force Research Laboratory .

[5] Hou, T., Lin, L., \& G, D. C. (1993). An empirical study of hybdrid inspection systems and allocation of inspection functions. International Journal of Human Factors in Manufacturing 3(4), 351-367.

[6] McCarthy, J. (2013, August 14). Audi teaches drives maintenance tips with augmented reality app. Retrieved from Luxurydaily: https://www.luxurydaily.com/audis-augmented-reality-app-teachesusers-how-to-maintenance/

[7] Olieveira, R., Farinha, T., Singh, S., \& Galar, D. (2013). An Augmented reality application to support maintenance-is it possible? Lappeenranta University of Technology, 260-271.

[8] Platonov, J., Heibel, H., Meier, P., \& Grollmann, B. (2006). A mobile markerless AR system for maintenance and repair. In proceedings of the 5th IEEE and ACM International Symposium on Mixed and Augmented Reality (ISMAR) (pp. 105-108). Washington: IEEE Computer Society.

[9] Prakash, D., \& Kumar, S. (2011). Implementation of Lean Manufacuturing Principles in Auto Industry. Industrial Engineering Letters, 1(1), 56-60.

[10] Samuely, A. (2015, November 13). Hyundai modernizes car owner's manual with augmented reality spin. Retrieved from Mobile Marketer: http://www.mobilemarketer.com/cms/news/softwaretechnology/21686.html

[11] Turpen, A. (2015, Nov 10). Hyundai Virtual Guide app updates the car owner's manual. Retrieved from Gizmag. http://www.gizmag.com/hyundai-introduces-3d-augmented-realityowners-manuals/40339/ 